\title{
A Pragmatic Study of Relational Identity in
}

\section{Bystander Intervention}

\author{
Xu Huang ${ }^{1}$ \\ ${ }^{1}$ Centre for Linguistics and Applied Linguistics, Guangdong University of Foreign Studies, Guangzhou, China \\ Correspondence: Xu Huang, Centre for Linguistics and Applied Linguistics, Guangdong University of Foreign \\ Studies, Guangzhou, China. E-mail: 18813962070@163.com
}

Received: January 20, 2018 Accepted: February 5, 2018 Online Published: May 14, 2018

doi:10.5539/hes.v8n2p81

URL: https://doi.org/10.5539/hes.v8n2p81

\begin{abstract}
Given that intervention has been relatively under-researched in pragmatics, this paper offers a linguistic-pragmatic examination of a case of bystander intervention, a notion which is generally known in social psychology. This study approaches the phenomenon of bystander intervention by analyzing discourse data transcribed from a video posted online. Drawing on participation status and relational identity theory, this paper investigates the issues of relational identity and relationships involved in an intervening interaction. The findings indicate that the intervener's relational identity is in a constant process of construction and negotiation, and the study also notices that three most prominent strategies in our case are employed that give rise to the effective intervention, namely humor, empathy and imposition of power, which might provide some insights into further research in this field.
\end{abstract}

Keywords: bystander intervention; participation status; relational identity; relationships; strategies

\section{Introduction}

Bystander intervention, a notion which is generally known in social psychology, refers to the social action by which a bystander steps in and attempts to prevent a wrongdoer from abusing a victim (Kádár \& Márquez-Reiter, 2015). The term proved highly resonant after a famous murder in which a young woman named Kitty Genovese was stabbed to death in the middle of a street in New York City while at least 38 witnesses had observed the attack - but none had even attempted to intervene. Although the attacker took over half an hour to kill Kitty Genovese, not one of the 38 people who watched from the safety of their own apartments came out to assist her and not even one lifted the telephone to call the police (Darley \& Latane, 1968). This phenomenon aroused broad attention from the society and was then extensively researched in social psychology (Darley \& Latane, 1968; Fischer et al., 2011; Latané \& Nida, 1981; Polanin et al., 2012), but it is relatively underexplored in pragmatics. Notably a practical value lies in approaching this social phenomenon from the linguistic-pragmatic perspective in that the systematic and theoretical analysis of language use and language meaning in bystander intervention based on naturalistic data could possibly shed light on the future application of linguistic devices or strategies employed to intervene. This paper aims to explore this field from the perspective of identity on the ground that the construction of an intervener's relational identity is crucial to the achievement of an effective intervention.

In the present paper, firstly we summarize the significance of the research on identity issues, then tentatively propose a model that might be applied in bystander intervention based on the participation status theory advanced by Goffman (1981) and promoted by Kádár and Haugh (2013). After a review of identity theory in bystander intervention, the above-mentioned model is adopted to the analysis of the intervener's relational identity. Given the implicated relationship between identity and relationships (Haugh et al., 2015), this paper also places a premium on the relationships among participants in bystander intervention so as to research the identity issue more thoroughly. In the analysis part, the study investigates how a middle-aged lady steps up against a seat grabber to discursively construct and negotiate her relational identity through the course of intervention, certainly the relationships between the intervener and other participants (mainly including the victim and the wrongdoer) are also explored. Additionally, this study also detects three most prominent strategies that give rise to the effective intervention, which might contribute to future inquiries in this field. 


\section{Theoretical Underpinnings}

Scarcely touched upon as bystander intervention was in pragmatics, Kádár and Márquez-Reiter (2015) pioneered the exploration of this field by studying the relationship between (im)politeness and participants' perceptions and understandings of moral principles by analyzing cases of bystander intervention drawn from WWYD (What Would You Do? It is a US hidden camera show), and by examining rituals of outspokenness in bystander intervention by drawing on the same data (Kádár \& De La Cruz, 2016). This paper aims to further a study into this field from another perspective-identity. The identity issue is worth of analysis for three possible reasons: firstly, the incorporation of identity theory into the participant status theory below is necessary to underscore the fluidity of one participant's role-relationship with others in bystander intervention; secondly, the construction of an intervener's identity as ratified side participant is a crucial precondition for intervention, the study of which can provide some insights into the communicative strategies employed to intervene; thirdly, the uncertainties of bystanders' transformation (into ratified side participants or not) and of their stances that contribute to the complexity of interpersonal relationships between participants involved in the intervention result in the dynamics of their relational identity such as identity negotiation. In the following section we will concentrate on how identity is related to participation status in bystander intervention, as well as its construction and negotiation process, and the implicated relationship between identity and relationships will also be briefly touched upon.

\subsection{Participation Status in Bystander Intervention}

With regards to participant types in the talk, Goffman (1981) proposes a participation framework. Briefly speaking, he suggests that in the whole there are three kinds of listeners to talk: the first is unratified participants who overhear the talk, but whether they are encouraged to do so or not remains unknown; the second is ratified participants who are not specifically addressed by the speaker (in the case of more than two-person talk); the third is also ratified participants who are specifically addressed, i.e. they are particularly directed by the speaker in an explicit or implicit way, and they are also more anticipated to show certain response to the speaker's words compared with the other ratified participants. Based on this theory, Kádár and Haugh (2013) then outlined different types of participation status, as illustrated in Figure 1.

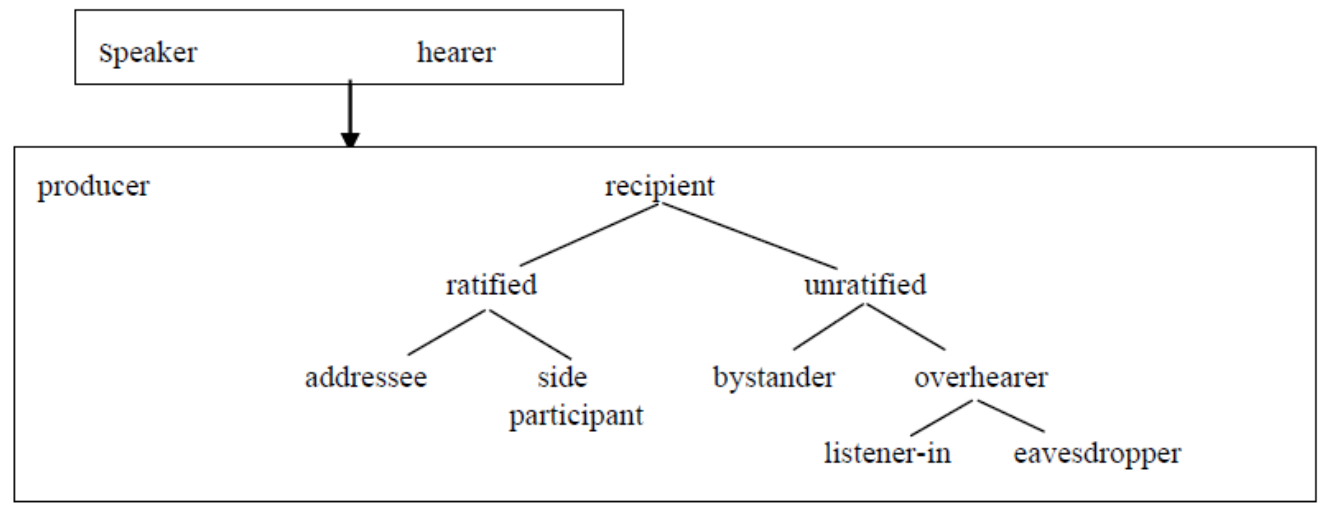

Figure 1. Types of participation status

In this revised model Kádár and Haugh (2013) strategically used the terms producer and recipient to replace speaker and hearer to avoid confusion with these commonly used folk terms, as well as to allow those nonconventional modes of communication, such as mediated forms of communication (not just through speech). Ratified participants refer to those who have the right to hold other participants (as well as themselves) morally responsible for the social actions and meanings that arise through that talk while unratified participants refer to those who do not have the right to hold the producer morally responsible (Kádár \& Haugh, 2013, p. 87). Based on this model, we tentatively propose a model that might be applied in bystander intervention, as shown in Figure 2.

According to Kádár and De La Cruz (2016), in the context of bystander intervention, a 'bystander' (or a group of bystanders), who is initially unratified to participate, is upgraded to ratified side participant(s) through the ritual of outspokenness which represents "the recurrent and expected dramatic action of stepping up against the committer or a group of committers of a seemingly immoral action"(p. 265). The intervener, by means of stepping in to stop an ongoing act of injustice or immorality, can surely be regarded as a ratified side participant and those bystanders who demonstrate any attempts to counter the wrongdoer can also be viewed as ratified side 
participants. Nevertheless, it can be argued that the justification of the presence of the overhearers is contingent upon the relationship between the wrongdoer and the victim: in many cases drawn from WWYD, two persons (or more) are intimately related to each other, so their interaction are not expected to be heard by others while those who do hear some parts of the talk can be categorized as overhearers; in other cases such as our case, two persons are completely strange to each other and their initial interaction occurs in a public domain, so it is seemingly not necessary to make a distinction between bystanders and overhearers. And that's why "overhearer" is followed by a question mark in Figure 2.

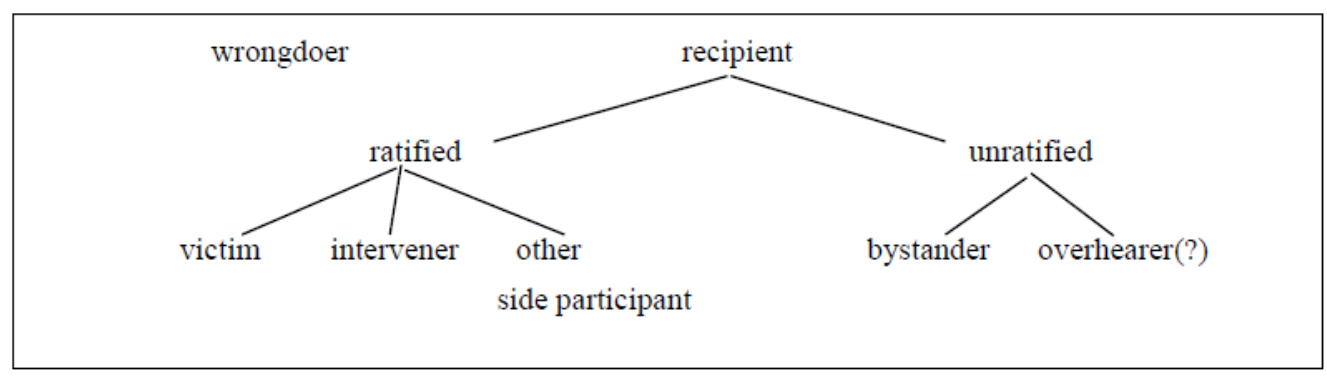

Figure 2. Participation status in bystander intervention

\subsection{Relational Identity in Bystander Intervention}

Identity, as a composite definition of the self (Baumeister \& Muraven, 1996), was widely studied in such diverse academic domains as sociological (e.g. Côté, 1996), psychological (e.g. Turner et al., 1987), microsociological (e.g. Ibarra, 1999; Stryker, 2008; Stryker \& Burke, 2000), social psychological (e.g. Cuhadar \& Dayton, 2011; Hogg \& Terry, 2000)and so on. As psychologists, sociologists and philosophers have long recognized that people have multiple identities based on attributes such as profession, gender, ethnicity, religion, nationality, organizational membership, and family role(s) (Ramarajan, 2014), a trichotomy of individual (or personal) identity, relational identity and collective (or group, social) identity was widely accepted (e.g. Brewer \& Gardner, 1996; Spencer-Oatey, 2007). But we will only focus on relational identity considering its pertinence to the current study.

According to Brewer and Gardner (1996), relational identity denotes the self-concept derived from connections and role relationships with significant others. Sluss and Ashforth (2007) also suggest that a relational identity, negotiated with others and through others, can be defined as the nature of one's role-relationship such as manager-subordinate and coworker-coworker. The interpretation of one's relational identity can thus be placed in a relational web where his/her relational identity is constructed through his/her relational work with others and may be negotiated as this web varies. In the context of bystander intervention, one's relational identity, tantamount to his/her role-relationship with others in a relational web mainly composed of the wrongdoer, the victim, and the intervener, can be roughly explained by incorporating the participation status model in Figure 2 . For instance, the intervener's relational identity, or his/her role-relationship with the wrongdoer, can be elucidated as ratified side participant-ratified participant. In our case, the wrongdoer, the victim and bystanders (including the potential intervener) co-construct a relational web and their relational identities can only be shaped and recognized by those belonging to the same relational community and would be otherwise impossible.

As for identity construction, we adopt the common view that identities are situationally and contextually constructed (Brubaker \& Cooper, 2000), for instance, when one gets on a train, his/her identity as a train passenger is immediately formed. According to Ramarajan (2014), identities are negotiated and formed through situated social interaction. In line with this idea, Spencer-Oatey (2007) also proposes, from interactional perspective, “...they not only enact elements of their personal, relational and collective selves through the process of social interaction, but they also negotiate and construct them, with the result that identities develop and emerge through interaction"(p. 642). In other words, through the course of social interaction an individual's identity could be constructed and negotiated. In bystander intervention - an unpredictable social interaction, an individual's relational identity can be constructed through his/her participation in a relational community mainly made up of the wrongdoer, the victim and the intervener, but the ratification of identity in the relational community might be challenged or threatened by the community members through the process of the intervening interaction. As stated above, the fluidity of participation status leads to the dynamics of participants' role-relationships with each other in bystander intervention, thus to the dynamics of their identities. For instance, a bystander, as an unratified participant, might be transformed into a ratified side participant through a ritual of 
outspokenness (Kádár \& De La Cruz, 2016). In turn, a ratified side participant might also be degraded to an unratified participant by keeping away from the intervention issue. It is worth noting that the fluidity of the intervener's relational identity is paralleled by the evolvement of his/her relationships with other participants which can serve as a reliable indicator of identity negotiation, so a considerable attention is also paid to the analysis of relationships.

As Arundale (2010) states that identities should be conceptualized in terms of individual systems and relationships in terms of social systems, given the individual-social dialectic, they are dialectically interrelated in social interactions. Spencer-Oatey (2007) also claims that an individual identifies him/herself through his/her relationship with others, such as marital partners, coworkers and friends. An individual's identity is constructed by his/her recognition of similarities and/or differences with others. In the cognitive process of perceiving the similarities and/or differences with others, an individual has in fact established an explicit or implicit relationship with them. To be more specific, one's relational identity is derived from his/her role-relationship with others, indicating that his/her relationship with others can serve as a direct reflection of relational identity that might be negotiated as this relationship evolves and shifts, hence the need for inquiring the relationships. As Haugh et al. (2015) also argues, "identities implicate relationships and relationships implicate identities"(p. 79), this paper revolves around both to study the intervener's relational identity in our case more thoroughly.

\section{Data}

As Kádár and De La Cruz (2016)states, it is difficult to collect data that portrays the abuse in interaction as abuse that triggers a ritual response(s) is a behavioral anomaly from a normative point of view. In reality, such events always happen so suddenly that leaves no time for collecting data. Whereas scholars have approached this phenomenon by analyzing data drawn from WWYD (Kádár \& De La Cruz, 2016; Kádár \& Márquez-Reiter, 2015), a reality show in which actors act out scenes of conflicts or some type of illegal activity, then hidden cameras focus on whether bystanders intervene or not, the data in the present study is drawn from a naturally occurring interaction videoed and posted online (see more on https://www.youtube.com/watch?v=j_or9jJRq0c). This video was recorded by a metro passenger who accidentally witnessed the whole process of bystander intervention on August 19th, 2015 on Shanghai No.8 Metro. Soon the uploaded video and related news reports instantaneously elicited an animated public discussion of the intervener and her rightful acts. Besides, some newspapers conducted a follow-up interview of the intervener. The detailed interview data is not included in this paper as it is not closely related to the present study (there are online reports about this interview, see more on http://guoqing.china.com.cn/2015-08/21/content_36373429.htm).

The video lasts 88 seconds in length, and is transcribed into the discourse data that contains about 294 words in total. There are altogether 8 participants involved in the intervention case that contributes to the intervening process to a varying degree. It is noteworthy that most participants in our case are Shanghai natives and they spoke the Shanghai dialect of Chinese. As only the intervener and the wrongdoer's discourses are subtitled in the video, the rest data has to be transcribed by a Shanghai native and checked by another two natives to ensure the accuracy of the transcript.

\section{Analysis}

In the second section, how participation status is associated with relational identity in bystander intervention is explained, this section will focus on how the intervener's relational identity is contextualized, constructed and negotiated in our case of bystander intervention. As stated above, this section will also examine the relationships between the intervener and other participants (mainly including the victim and the wrongdoer) in order to inquire the intervener's relational identity in a more comprehensive way. And alignment and disalignment, two terms derived from social psychology, are commonly used to relate to the analysis of relationships as they implicitly reveal one's participation status in the talk (Goffman, 1981; Kádár \& Haugh, 2013), hence relational identity. In other words, the ratification of one's relational identity in bystander intervention can to some extent be accounted for by his/her alignment with either the victim or the wrongdoer. For instance, the intervener's alignment with the victim actually indexes her agreed identity as ratified side participant who is empowered by the victim, though mostly implicitly, to give voice to what she regards as the opinion of the public (Kádár \& Márquez-Reiter, 2015).

\subsection{Constructing Identity}

Just prior to extract 1, a woman (S1) with a bandaged arm rushes on the coach of Shanghai No.8 Metro and quickly occupies the seat of a young girl (S2). Then she keeps squeezing the girl and even hits her. The following two extracts show how a middle-aged lady (S3) intervenes and constructs her identity as ratified side-participant. 


\section{Extract one}

1 旁观者 1: 你们这样, 给她拍张照片传到微信上去。

\section{S4: You guys, photo her and send the pic to Wechat.}

(The seat grabber hitting the girl)

2 旁观者 2: 哎 吆 哟 哟。

S5: (uttering an exclamation of surprise)

3 大妈: 是的呀。你不要打她, 我关照 (告诉) 你。

S3: Yes, that's right. You stop hitting her, I inform you.

4 女孩: 你手不是好的吗?

S2: Aren't your hands just all good?

5 大妈: 你手不是蛮好的吗?

\section{S3: Aren't your hands just all good?}

S1, who asserts that the injured should be granted the privilege of seats priority on the metro, initially places herself at an advantageous position on the one hand as a wounded person who legitimizes her behavior in her own interpretation, on the other hand as an elder person who assumes an age advantage over the socially inexperienced young girl. Despite her not-too-serious injury on the arm, at least judged from her subsequent offensive behaviors, S1 abuses this taken-for-granted right and crosses the moral line. Angrily, one of bystanders (S4) prompts other bystanders to take a photo of S1 and send it to Wechat (the free messaging \& calling app that allows you to easily connect with family \& friends across countries) - in line 1. Instead of directly intervening in the abusive action, S4 gives her moral judgment (Kádár \& Márquez-Reiter, 2015) that S1's action is morally inadmissible that requires open evaluation, and her suggestion to expose the image of S1 makes manifest what stance S4 takes in virtue of that posting one's situated image on the Internet to open evaluation often conveys a negative judgment of this person in Chinese culture, especially in this situation. Here from the perspective of S4 and side participants-to-be (Kádár \& De La Cruz, 2016), S1 is regarded as a wrongdoer who deliberately infringes upon conventional social norms that in a public domain any kinds of acts of injustice or immorality shouldn't be committed and who also violates the rules implemented by the Shanghai Metro Operation that all the passengers should behave with civility and decency and are prohibited from creating conflicts (http://service.shmetro.com/ckxz/index.htm).

Although S4 does not trigger any overt or covert conflict with S1, she intends to draw more attention as she directly addresses other bystanders with a second personal pronoun "you". And more participants are indeed attracted. As S1 still squeezes and hits the girl, in line 2, a bystander (S5) utters an exclamation of surprise while a middle-aged lady (S3) besides the victim steps up against the abuser in the form of on-record imperatives-in line 3. The illocutionary force is intensified by the utterances- "I inform you", which explicitly demonstrates the stance S3 takes and triggers an overt conflict in between. In the meanwhile, S3 wraps her arm around S2, protecting her from further abuse. It is noteworthy that the body language of S3 (wrapping her arm around S2) is a common sign of protective alignment (Kádár \& De La Cruz, 2016). By doing so, S3 displays her identity as ratified side participant who cannot remain blind witnessing the abusive situation deteriorating any longer. In line 4, S2 questions the seriousness of S1's injury as the latter frequently hits the former with her bandaged arm, and S3 raises the same doubt-in line 5. In fact, the negatively formulated question that involves "aren't you" indicates that $\mathrm{S} 2$ is making an assertion that $\mathrm{S} 1$ is not seriously injured rather than asking a neutral question (Alfahad, 2015), and S3's echoing indexes her alignment with S2 and thus disalignment with S1. By echoing, S3 also announces to the wrongdoer her identity as ratified side participant who is entitled to give voice to what she holds to be right.

\section{Extract two}

6 大妈: 今朝我就光火了, 我就不起来了, 我就帮这个小姑娘了。

S3: Now I am just very pissed off. And I won't get up. This girl is under my cover now.

7 大妈: 谁码子更大来, 我真搞不懂了, 我 200 斤的人搞不过你啊。

S3: Who is the bigger one here? I just don't get it. You think this 200-jin body won't beat your down.

8 (bystanders laughing...)

In line 6, firstly S3 displays her emotional response that she is angered by S1's stepped-up abuse. As Culpeper 
(2011) suggests that causing offence is initiated by a speaker through various kinds of impoliteness triggers, and taking offence "by the recipient in which he or she construes the actions or conduct of the prior speaker (or some other person or group of persons) as offensive" (Haugh, 2015, p. 37). In this case, although S1 does not verbally offend S3, yet her behavior is way too offensive that deploying "impoliteness" as a lens to interpret her behavior is far not sufficient. S3 takes offence caused by S1's socially and morally unacceptable behavior, and then she states her attitudinal stance that she will not stay out of it, which serves as a declaration that a confronting and conflictual relationship is formally established between her and S1.

In line 7, S3 claims that she has a bigger size and weighs about two hundred jin by which she employs a strategy of physical power imposition on S1 in a self-mocking way as she clarifies the fact that she weighs less than two hundred jin in a follow-up interview. While her utterances immediately arouse laughter from other bystanders - in line 8, they also function as a strategy of humor that can be deployed to create a sense of in-group identity as well as to mitigate potentially face-threatening acts (Moody, 2014). Here the purpose to soften the illocutionary force of her utterances and mitigate the impact that this face-threatening act might have is not salient, but it helps to create a temporary light-hearted atmosphere so that more side participants-to-be might be recruited. By deploying this strategy, S3 not only succeeds in introducing information favorable to herself and unfavorable to others in aggressive interchanges (Goffman, 2005), but also recruits more bystanders and more side participants-to-be (Kádár \& Márquez-Reiter, 2015) to form an in-group identity. Here S3 also identifies herself as a ratified outspoken person (Kádár \& De La Cruz, 2016) who is capable to intervene with her physical power advantage.

\subsection{Reinforcing Alignment}

As S3 constructs her identity as ratified side participant, she simultaneously establishes an alignment with the victim that is reinforced by the involvement of a second and a third side participant, as reflected in the following extract.

\section{Extract three}

9 抢座女: () 死掉了。

\section{S1: (uttering negatively-loaded taboo words).}

10 大妈: 挤死了! 一把年纪了, 以为我搞不过你啊。阿姨帮我拿下, 妹妹坐, 妹妹坐这边。

S3: Too damn crowded! At my age, you think I won't beat you down. Take this for me, auntie. Come sis, sit here.

11 旁观者 3: 小朋友坐到这边来。

S6: Little girl, sit here.

12 旁观者 4: 有毛病啊你。

\section{S7: Something wrong with your brain.}

(the victim moving to the other side)

In line 9, S1 mutters against the intervener with unrecognizable expressions. Judged by her speaking tone and several identifiable words, S1 is opposing S3 by uttering the expletives. In response, S3 invokes her age advantage while this age advantage that $\mathrm{S} 1$ initially assumes, is canceled due to the participation of an even elder person-S3. Here with her negatively-loaded taboo words, S1's public image as an immoral person is emphasized and her disalignment with S3 is strengthened, demonstrated by S3's reinforced power imposition in the form of a rhetorical question that she could beat S1 down. On the other hand, S3 is publicly forming a close rapport with S2 by holding S2 tightly under her arm. Additionally, S3's reference to S2 as her younger sister (which is pronounced meimei in Chinese) may also be an indication that the former attempts to draw the latter to her alliance. In other words, S3 utilizes a relational mode of identification in which she identifies S2 in a relational web, in this case, a web of sistership. In so doing, S3 explicitly establishes an affiliative and aligned relationship with S2 (Brubaker \& Cooper, 2000), which helps to increase the ratification of her identity.

In line 11, a second side participant (S6) echoes what S3 previously suggests to S2, coupled with her personal reference to S2 as "little girl" (which is pronounced xiao pengyou in Chinese), which indexes that she will align with S3 and her attempt to offer some help. And the victim's immediate reaction to move to the other side signals an acceptance of their suggestion and a reinforcement of the alignment which grants members of this alignment the right to voice for S2 (due to her passive status). In line 12, another bystander (S7) is transformed into a ratified side participant through a ritual of outspokenness (Kádár \& De La Cruz, 2016). In response to S1's 
abusive behaviors, $\mathrm{S} 7$ gives her judgment that $\mathrm{S} 1$ is psychologically ill by directly addressing $\mathrm{S} 1$ with a second personal pronoun "you". Clearly S7 intends to portray S1 as a mentally disturbed person whose behavior could never be interpreted from the perspective of a normal person. Here it is manifest that both S6 and S7 attempt to stand by S2's side, which contributes to reinforcing the alignment already established by S3 and S2. In turn, their alignment with S2 can reinforce the ratification of their participation status as ratified side participants.

\subsection{Negotiating Identity}

Although S3 announces to S1 her alignment with S2, hence her participant status in the relational community as a ratified side participant, this participant status is intentionally destroyed by S1 that contributes to S3's identity negotiation, as shown in the following extract.

\section{Extract four}

\section{3 大妈: 我真是一下子光火了, 真是的。}

\section{S3: I am just so pissed off, damn.}

\section{4 抢座女：跟你有什么关系？!}

\section{S1: Isn't it any of your business?!}

15 大妈: 跟我有什么关系, 跟我一点关系都没有, 本来一点关系都没有。

\section{S3: Isn't it any of my business, none of my business, it had been none of my business.}

16 抢座女：那么你干嘛，你畜生啊。

\section{S1: But look what you did, you animal.}

17 大妈: 呵呵, 我也不晓得, 我也搞不清楚了。

\section{S3: Hehe, I don't know, I can't get it through, either.}

In line 13, S3 retakes offence while her disalignment with $\mathrm{S} 1$ is temporarily maintained as $\mathrm{S} 1$ keeps silent. Nevertheless, this situation is quickly altered with the voicing of S1-in line 14. S3's relational identity as ratified side participant is publicly denied by $\mathrm{S} 1$ who intends to treat $\mathrm{S} 3$ as an unratified participant and perceive her as an intrusion in this conversation, which is accomplished by foregrounding the fact that $\mathrm{S} 3$ has nothing to do with this issue. Thus S3's relational identity as ratified side participant is questioned and negotiated as an outsider of this relational web.

Instead of refuting the previous assertion made by S1, in line 15, S3 seemingly agrees with $\mathrm{S} 1$ in the form of repeating her words by which S3 confirms her identity as unratified participant, at least at the discursive level. However, this newly-negotiated identity is mock and ruined soon with the progression of the interaction. Still in line 15, S3's deliberate repetition of her prior statement that it had been none of her business in the first place reveals that she attempts to convey the opposite of what it means literally. Herein lies a conversational implicature in the sentence - "It had been none of my business", which implies that the situation of S3's initial disassociation with this issue is changed by S1's aggravating behaviors, which can be underpinned by what S3 states in a follow-up interview in which she justifies her necessary and prompt intervention by clarifying the cause and effect. However, S3's intended message is not successfully conveyed while her literal agreement is taken advantage of by $\mathrm{S} 1$ to exclude the intervener from this interaction-in line 16. To vent her strong discontent over S3's intervention, S1 insults S3 with the negatively-loaded taboo item "animal". By doing so, S1 still attempts to deny the ratification of S3's relational identity as side participant. S3, however, demonstrates that she disdains to reply S1 in the form of uttering "hehe" and expressing negative meanings by which she abandons her mock identity as unratified participant regardless of S1's deliberate denial of her participation status.

\subsection{Renegotiating Identity}

It is pertinent to note that during their argument, someone on the same bench actively offers his seat to S2 who moves to the other side, thereby making enough space for S3 and S1. To ameliorate the situation, a fourth side participant (S8) thus involves, aiming to mediate between S1 and S3 which contributes to S3's identity renegotiation, as reflected in the following extract.

\section{Extract five}

18 旁观者 5: 哎哟, 你也不要说她了, 现在坐着不是蛮好嘛。

\section{S8: Aiyo, you may stop judging her, isn't so comfy for all of you now?}

19 大妈: 我一把年纪还搞不过你呀, 我也昏过去了, 这点肉白长了, 真的这些年饭白吃了。 
S3: At my age you think I won't beat you down, I'm gonna pass out, (if I won't beat you down) I would be sorry for all the rice $I$ have eaten and all the flesh $I$ have grown.

(hitting the victim)

In line 18, S8 directly addresses S3 to stop judging S1 and to maintain the current state in the form of mitigated linguistic devices. These linguistic devices, such as the Chinese character "ma" known as a downtoner (Skewis, 2003), are utilized to tone down the negative impact of her imposition on S3. By doing so S8 assumes a role of mediator who aims to reconstruct a non-conflictive atmosphere that should has been shared by all passengers in a coach domain, implicitly deemphasizing the presence of the intervener. It can be argued that S8 involves in the interaction to mediate, which grants her the ratification of the participation status as a side participant, hence the right to give voice to what she holds to be appropriate, i.e. there is no need for S3's further intervention. With S8's mediation, S3's relational identity as ratified side participant is again negotiated.

However, regardless of S8's mediation, S3 regains her relational identity as ratified side participant by invoking age advantage and physical power advantage again to intervene in order to prevent $\mathrm{S} 2$ from further abuse, and by directly accentuating her determination to intervene-“" if I won't beat you down), I would be sorry for all the rice I have eaten and all the flesh I have grown". In this way, S3 again announces to both S1 and S8 her relational identity as ratified side participant. Nevertheless, it seems that all of S3's imposition of power fails to stop S1 as she continues to hit S2 with her bandaged arm.

\subsection{Strengthening Identity}

As S1 abuses S2 again despite the intervention, S3 employs a strategy of empathy by which she conveys her moral judgment of S1 and simultaneously strengthens her relational identity, as reflected in the following extract.

\section{Extract six}

20 大妈：你干啥?

\section{S3: What you doing?}

21 抢座女: 我凭什么不能打她?

S1: Why on the earth I can't hit her?

22 大妈: 你干嘛打她, 你凭什么打人?

S3: Why the hell you hit her. What gives you the right to hit her?

23 抢座女: 因为她不让我。

\section{S1: Cause she did not give the seat.}

24 大妈: 哎哟, 我真是碰到赤佬了, 这么多人已经让你让到现在了。

S3: Aiyo, I literally met a thug. By now so many persons have let you do your way.

25 大妈: 哎哟, 我真的是要昏过去了。

\section{S3: Aiyo, I am gonna pass out.}

\section{(S1 stops to abuse)}

In line 20, S3 steps up against S1 of her abusive behavior by physically protecting S2 from further attack and verbally delegitimizing her behavior. Here S1 continues to cast herself as a privileged person as she implies that other passengers should offer their seats to her while those who do not should be hit. In line 24, it is obvious that her self-positioning as a privileged person (Van Langenhove \& Harré, 1999) is challenged by S3 who reacts by making an appeal to personal rights. By doing so, S1 is deliberately positioned (Gu et al., 2014) by S3 as an immoral person who overtly violates S2's personal rights. To draw more attention from other bystanders-in line 24, S3 employs a strategy of empathy, i.e. she imagines herself in another's place and understand the other's feelings, desires, and reactions (Wynn \& Wynn, 2006), which may achieve three interactional effects.

Firstly, after the intervening failure by means of S3's imposition of age and physical power, S3 tries to persuade S1 by directly addressing her with emotional appeal. In such a way, S3 aims to awaken S1's conscience and her sense of morality. Secondly, by feeling what others feel, S3 covertly intends to recruit more side participants-to-be to align with her and S2 since S1 still won't stop her abuse. Thirdly, by exposing S1's socially and morally inadmissible behavior and putting more bystanders in the position of victims, S3 means to make salient S1's public image as a morally bad person, thereby increasing the justification for her intervention and consolidating her relational identity as ratified side participant. Therefore, S3 also strengthens her relational 
identity by employing such a strategy. After all the efforts to intervene, S1 stops her abusive actions.

It is noteworthy that all the six extracts are consecutive, and have only been separated for convenient analysis.

\section{Discussion}

It goes without saying that in bystander intervention, an intervener's identity construction as ratified side participant is crucial to the intervening process, thus impacting the effect of intervention. In the case of acts of injustice or immorality between two intimate persons (see examples on Kádár \& Márquez-Reiter, 2015) or strangers, the wrongdoer generally intends to exclude the intervener from their interaction, in other words, to unratify the intervener's relational identity by making an appeal to the conventional norms of not entering into others' private spaces or avoiding conflicts, which requires the intervener to handle strategically to construct and maintain his/her identity as ratified side participant. The data studied in the present paper indicates that the intervener's relational identity is in a constant process of construction and negotiation, which can be illustrated by Figure 3.

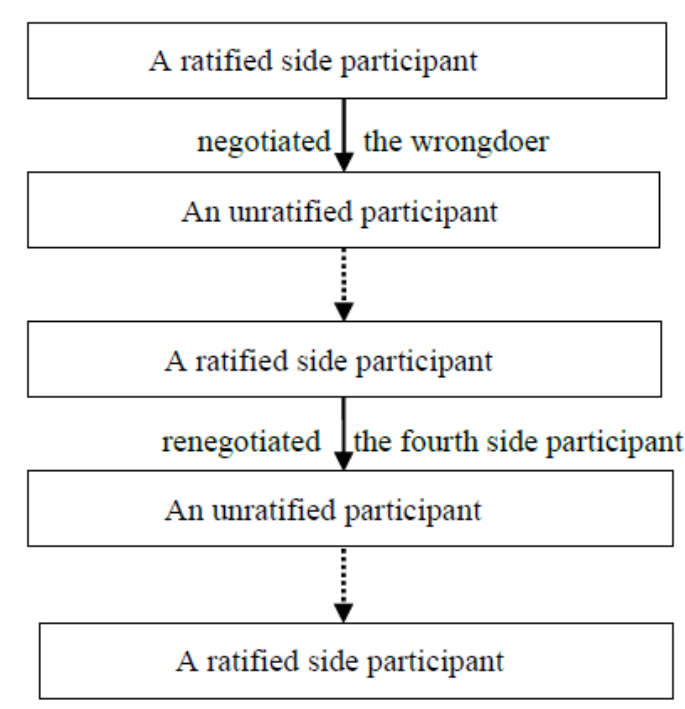

Figure 3. The dynamics of the intervener's identity

The solid arrows represent the impacts on the intervener's identity and the broken ones signal her own efforts to reseize her identity: firstly the intervener constructs her identity as ratified side participant by stepping up against the wrongdoer, then her relational identity is deliberately denied by the wrongdoer who identifies her as an unratified participant of this interaction, while the intervener legitimizes her intervention by implying that the wrongdoer's behavior is socially and morally inadmissible, thus regaining her identity as ratified side participant. Later as the situation seems to take a turn for the better, a fourth side participant involves and assumes a role of mediator, in an attempt to deny the intervener's relational identity again, which leads to her identity renegotiation. However, the wrongdoer's stepped-up abuse justifies the intervener's engagement, which contributes to reacquiring her relational identity as ratified side participant.

And the intervener's relationships with other participants, as a reliable indicator of identity negotiation, are also discussed in this paper and mainly manifested by alignment and disalignment, as shown in Figure 4.

The solid arrows represent the direction of overt conflicts: the wrongdoer initially triggers a conflict with the victim, then the intervener involves and enters a conflict with the wrongdoer. The broken arrows pointing toward the wrongdoer indicate covert conflicts with the victim and other side participants. It is noteworthy that the victim is always in a passive position due to her inability to declare an overt conflict with the wrongdoer. The full lines represent alignment formed: the intervener aligns with the victim through a ritual of outspokenness (Kádár \& De La Cruz, 2016), then other side participants subsequently join in the alignment. The dashed line represents alignment attempt: the third side participant only demonstrates an attempt to align with the victim. 


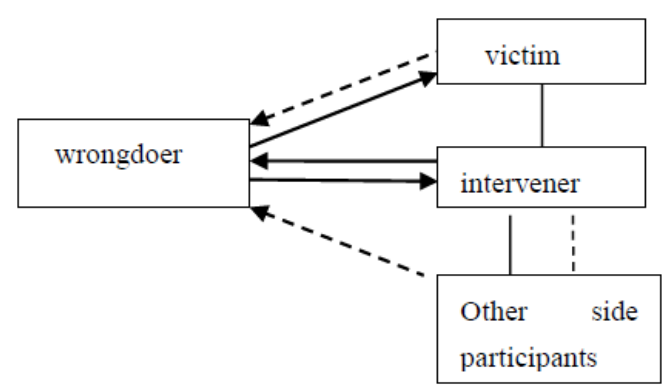

Figure 4. The dynamics of relationships

\section{Conclusion}

In the current study, we have explored and analyzed a typical case of bystander intervention, a notion generally known in social psychology which is rarely touched upon in pragmatics. By focusing on the intervener's relational identity and her relationships with other participants, we find that the intervener is always endeavoring to construct and consolidate her relational identity as ratified side participant despite other participants' negotiation and renegotiation of her identity, by which she eventually achieves an effective intervention. In this case, we also find that the effective intervention involves three most prominent strategies employed to step up against the wrongdoer: humor, imposition of power and empathy. Humor and empathy in this case are deployed to recruit more side participants and draw them to align with the victim while imposition of age and physical power serves to prevent the wrongdoer from continually abusing the victim. By elaborating on the intervener's relational identity and these three strategies, we consider that this might make some modest contribution towards future research on bystander intervention in pragmatics and fill an important knowledge gap in this field.

However, such paralinguistic cues as gestures, facial expressions, prosody and so on are either missing or not deeply examined when analyzing identity and relationships in our study. Moreover, due to the limitation of one case of discourse data, the study has only made a very preliminary inquiry into one aspect of bystander intervention and its possible findings are cultural specific, meaning that a different intervening mechanism might be applied in a culturally different setting. Therefore, more studies need to be conducted to explore the field of bystander intervention across cultures and this might be a new direction for future studies.

\section{References}

Alfahad, A. (2015). Aggressiveness and deference in Arabic broadcast interviews. Journal of Pragmatics, 88, 58-72. https://doi.org/10.1016/j.pragma.2015.08.009

Arundale, R. B. (2010). Constituting face in conversation: Face, facework, and interactional achievement. Journal of Pragmatics, 42(8), 2078-2105. https://doi.org/10.1016/j.pragma.2009.12.021

Baumeister, R. F., \& Muraven, M. (1996). Identity as adaptation to social, cultural, and historical context. Journal of Adolescence, 19(5), 405-416. https://doi.org/10.1006/jado.1996.0039

Brewer, M. B., \& Gardner, W. (1996). Who is this" We"? Levels of collective identity and self representations. Journal of personality and social psychology, 71(1), 83. https://doi.org/10.1037/0022-3514.71.1.83

Brubaker, R., \& Cooper, F. (2000). Beyond "identity". Theory and society, 29(1), 1-47. https://doi.org/10.1023/A:1007068714468

Côté, J. E. (1996). Sociological perspectives on identity formation: The culture-identity link and identity capital. Journal of Adolescence, 19(5), 417-428. https://doi.org/10.1006/jado.1996.0040

Cuhadar, E., \& Dayton, B. (2011). The Social Psychology of Identity and Inter-group Conflict: From Theory to Practice. International Studies Perspectives, 12(3), 273-293. https://doi.org/10.1111/j.1528-3585.2011.00433.x

Culpeper, J. (2011). Impoliteness: Using language to cause offence: Cambridge University Press. https://doi.org/10.1017/CBO9780511975752

Darley, J. M., \& Latane, B. (1968). Bystander intervention in emergencies: diffusion of responsibility. Journal of personality and social psychology, 8(4p1), 377. https://doi.org/10.1037/h0025589

Fischer, P., Krueger, J. I., Greitemeyer, T., Vogrincic, C., Kastenmuller, A., Frey, D., . . Kainbacher, M. (2011). The bystander-effect: a meta-analytic review on bystander intervention in dangerous and non-dangerous 
emergencies. Psychol Bull, 137(4), 517-537. https://doi.org/10.1037/a0023304

Goffman, E. (1981). Forms of talk: University of Pennsylvania Press.

Goffman, E. (2005). Interaction ritual: Essays in face to face behavior: AldineTransaction.

Gu, M. M., Patkin, J., \& Kirkpatrick, A. (2014). The dynamic identity construction in English as lingua franca intercultural communication: A positioning perspective. System, 46, 131-142. https://doi.org/10.1016/j.system.2014.07.010

Haugh, M. (2015). Impoliteness and taking offence in initial interactions. Journal of Pragmatics, 86, 36-42. https://doi.org/10.1016/j.pragma.2015.05.018

Haugh, M., Chang, W. L. M., \& Kádár, D. Z. (2015). "Doing deference": Identities and relational practices in Chinese online discussion boards. Pragmatics, 25(1), 73-98. https://doi.org/10.1075/prag.25.1.04hau

Hogg, M. A., \& Terry, D. I. (2000). Social identity and self-categorization processes in organizational contexts. Academy of Management Review, 25(1), 121-140.

Ibarra, H. (1999). Provisional selves: Experimenting with image and identity in professional adaptation. Administrative science quarterly, 44(4), 764-791. https://doi.org/10.2307/2667055

Kádár, D. Z., \& De La Cruz, M. (2016). Rituals of outspokenness and verbal conflict. Pragmatics and Society, 7(2), 265-290. https://doi.org/10.1075/ps.7.2.05kad

Kádár, D. Z., \& Haugh, M. (2013). Understanding politeness: Cambridge University Press. https://doi.org/10.1017/CBO9781139382717

Kádár, D. Z., \& Márquez-Reiter, R. (2015). (Im) politeness and (im) morality: Insights from intervention. Journal of Politeness Research, 11(2), 239-260.

Latané, B., \& Nida, S. (1981). Ten years of research on group size and helping. Psychological Bulletin, 89(2), 308. https://doi.org/10.1037/0033-2909.89.2.308

Moody, S. J. (2014). "Well, I'ma Gaijin": Constructing identity through English and humor in the international workplace. Journal of Pragmatics, 60, 75-88. https://doi.org/10.1016/j.pragma.2013.11.001

Polanin, J. R., Espelage, D. L., \& Pigott, T. D. (2012). A meta-analysis of school-based bullying prevention programs' effects on bystander intervention behavior. School Psychology Review, 4l(1), 47.

Ramarajan, L. (2014). Past, Present and Future Research on Multiple Identities: Toward an Intrapersonal Network Approach. The Academy of Management Annals, 8(1), 589-659. https://doi.org/10.1080/19416520.2014.912379

Skewis, M. (2003). Mitigated directness in Honglou meng: directive speech acts and politeness in eighteenth century Chinese. Journal of Pragmatics, 35(2), 161-189. https://doi.org/10.1016/S0378-2166(02)00084-X

Sluss, D. M., \& Ashforth, B. E. (2007). Relational identity and identification: Defining ourselves through work relationships. Academy of Management Review, 32(1), 9-32. https://doi.org/10.5465/AMR.2007.23463672

Spencer-Oatey, H. (2007). Theories of identity and the analysis of face. Journal of Pragmatics, 39(4), 639-656. https://doi.org/10.1016/j.pragma.2006.12.004

Stryker, S. (2008). From Mead to a structural symbolic interactionism and beyond. Annu. Rev. Sociol, 34, 15-31. https://doi.org/10.1146/annurev.soc.34.040507.134649

Stryker, S., \& Burke, P. J. (2000). The past, present, and future of an identity theory. Social psychology quarterly, 284-297. https://doi.org/10.2307/2695840

Turner, J. C., Hogg, M. A., Oakes, P. J., Reicher, S. D., \& Wetherell, M. S. (1987). Rediscovering the social group: A self-categorization theory: Basil Blackwell.

Van Langenhove, L., \& Harré, R. (1999). Introducing positioning theory.

Wynn, R., \& Wynn, M. (2006). Empathy as an interactionally achieved phenomenon in psychotherapy: Characteristics of some conversational resources. Journal of Pragmatics, 38(9), 1385-1397. https://doi.org/10.1016/j.pragma.2005.09.008

\section{Copyrights}

Copyright for this article is retained by the author(s), with first publication rights granted to the journal.

This is an open-access article distributed under the terms and conditions of the Creative Commons Attribution license (http://creativecommons.org/licenses/by/4.0/). 